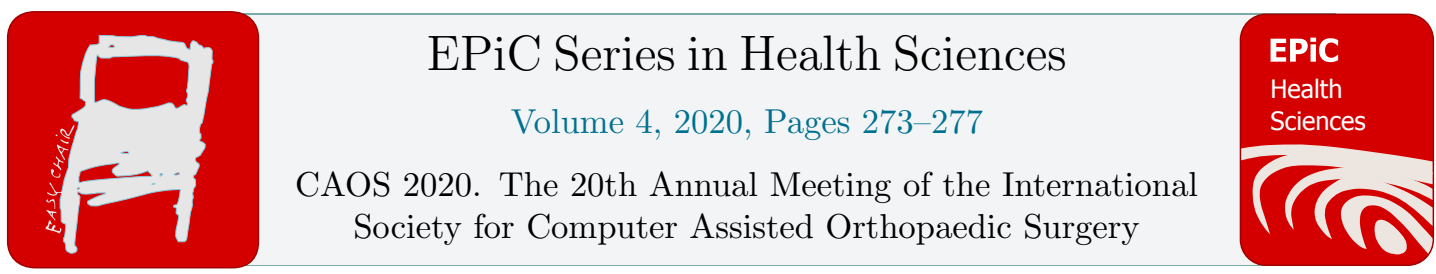

\title{
High Offset Stems are Protective of Dislocation in High Risk Total Hip Arthroplasty
}

\author{
Jonathan M. Vigdorchik ${ }^{1}$, Abhinav K. Sharma ${ }^{1}$, Ameer M. Elbuluk ${ }^{1}$, Kaitlin \\ M. Carroll ${ }^{1}$, David J. Mayman ${ }^{1}$, and Jay R. Lieberman ${ }^{2}$ \\ ${ }^{1}$ Hospital for Special Surgery, New York, NY \\ ${ }^{2}$ Keck School of Medicine of USC, Los Angeles, CA \\ vigdorchikjehss.edu, abhinav.sharma404@gmail.com
}

\begin{abstract}
Background: Spinal stiffness has been shown to increase risk of dislocation due to impingement and instability. Increasing anteversion of the acetabular component has been suggested to prevent dislocation, but little has been discussed in terms of femoral or global offset restoration. The purpose of this study is to quantify dislocation rates after primary THA using standard versus high offset femoral components and to determine how differences in offset affect impingement-free range of motion in a stiff spine cohort using a novel impingement model. Methods: 12,365 patients undergoing THA from 2016-2018 were retrospectively reviewed to determine dislocation rates and utilization of standard versus high offset stems. For 50 consecutive patients with spinal stiffness, a CT-based computer software impingement modeling system assessed bony or prosthetic impingement during simulated range of motion. The model was run 5 times for each patient with varying offsets. Range of motion was simulated in each scenario to determine the degree at which impingement occurred. Results: There were 51 dislocations for a $0.41 \%$ dislocation rate. Total utilization of high offset stems in the entire cohort was $49 \%$. Of those patients who sustained a dislocation, 49 (96\%) utilized a standard offset stem. The impingement modeling demonstrated 5 degrees of added range of motion until impingement for every $1 \mathrm{~mm}$ offset increase. Conclusion: In the impingement model, high offset stems facilitated greater ROM before bony impingement and resulted in lower dislocation rates. In the setting of high-risk THA due to spinal stiffness, surgeons should consider the use of high-offset stems and pay attention to offset restoration.
\end{abstract}

\section{Introduction}

A stiff spine or spinal fusion has been shown to increase risk of dislocation due to decreased pelvic rollback when transitioning from a standing to a seated position resulting in impingement and 
instability (Figure 1). Increasing anteversion of the acetabular component has been suggested to prevent dislocation, but little has been discussed in terms of femoral or global offset restoration.

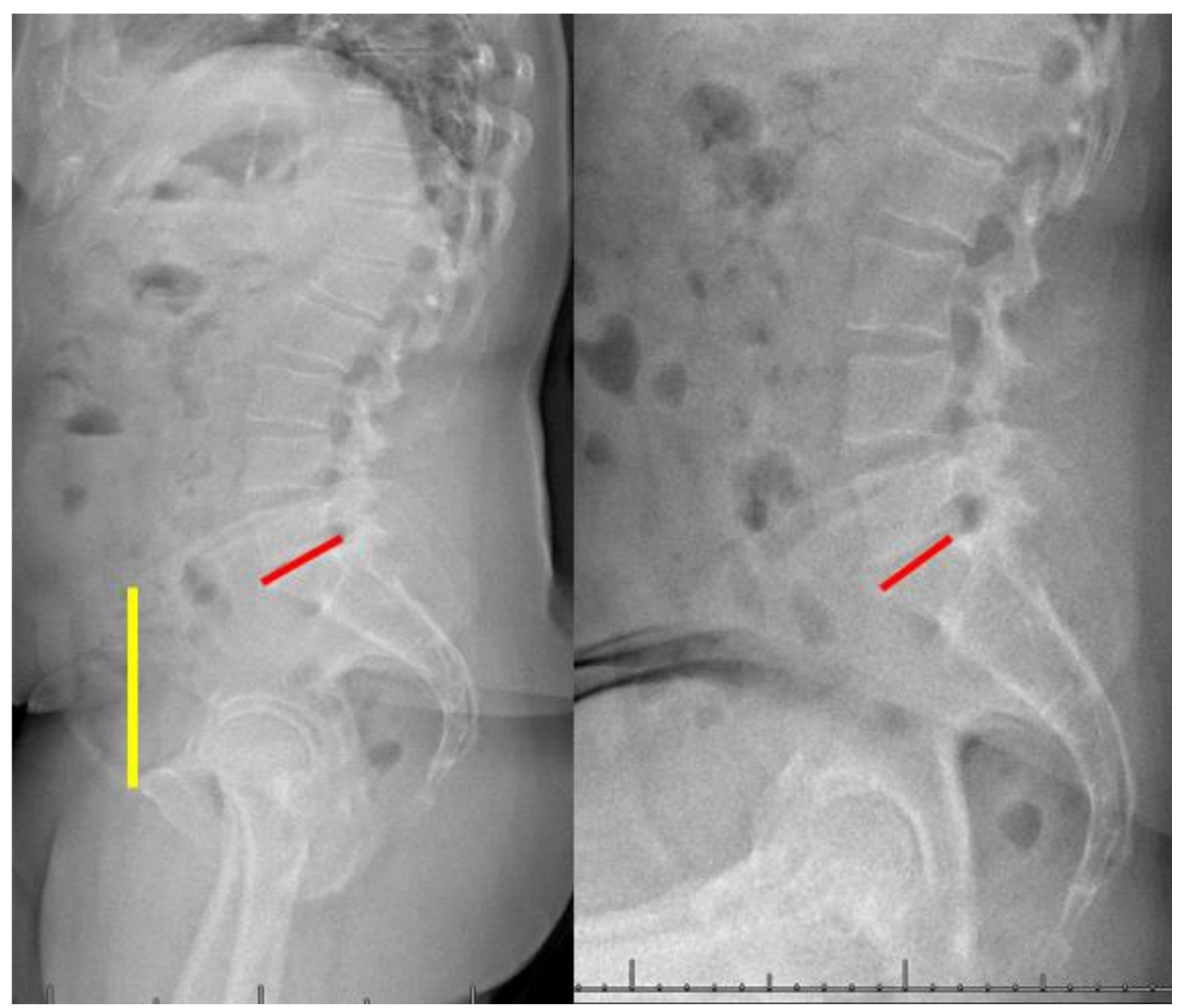

Figure 1: Standing and seated lateral radiographs of the spine and pelvis illustrating the sacral slope (red line over superior plate of S1) and anterior pelvic plane (yellow line from the two anterior superior iliac spines and pubic symphysis). There is no change in the sacral slope (red line) between the two positions. This indicates failure of pelvic rollback and biological opening of the acetabulum during the transition from standing to sitting due to spinal stiffness and leads to increased risk of impingement.

Matsushita et al. and McGrory et al. both reported that the use of high offset femoral components resulted in improved ROM and decreased bony impingement ${ }^{1-3}$. A protective mechanism to avoid instability in a stiff spine cohort of patients is to increase the offset of the femoral stem to move the trochanter away from the pelvis to prevent bony impingement.

The purpose of this study is two-fold: first, to determine the clinical impact of using high offset femoral components on dislocation rates after primary THA, and second, using a novel CT-based computer-generated impingement model, to determine how differences in offset affect rates of impingement-free range of motion in a high-risk stiff spine cohort. 


\section{Materials and Methods}

A series of 12,365 consecutive patients undergoing THA from 2016-2018 at a single institution were retrospectively reviewed to determine rates of dislocation. THAs were all performed via the posterior approach with posterior soft tissue capsular repair. All THAs were performed with meticulous removal of anterosuperior and posteroinferior osteophytes, and careful attention to restoring leg-length. Postoperatively, the only hip precautions maintained were no crossing of the legs past the midline for a period of six weeks. Implant information was evaluated for the utilization of high versus standard offset stems, and rates of subsequent dislocations recorded for each cohort.

For 50 consecutive patients with a stiff lumbar spine, a CT-based computer software impingement modeling system was used to assess bony or prosthetic impingement during simulated range of motion. The model was run 5 times for each patient with varying offsets, creating five impingement model conditions. Range of motion (flexion internal rotation, extension external rotation) was simulated in each scenario to determine the degree at which anterior and posterior impingement occurred.

\section{Results}

There were 12,365 THAs performed via the posterior approach from 2016-2018. Of these, there were 51 dislocations for a $0.41 \%$ dislocation rate. Total utilization of high offset stems in the entire cohort was $49 \%$. Of those patients who sustained a dislocation, $49(96 \%)$ received a standard offset stem.

The impingement modeling demonstrated 5 degrees of added range of motion until impingement for every $1 \mathrm{~mm}$ offset increase.

\begin{tabular}{|c|c|c|c|}
\hline $\begin{array}{c}\text { Impingement } \\
\text { Model Condition }\end{array}$ & $\begin{array}{l}\text { Acetabular Cup } \\
\text { Position }\end{array}$ & Stem Type & $\begin{array}{l}\text { Range of Motion Until } \\
\text { Impingement }\end{array}$ \\
\hline \multirow[t]{2}{*}{ Condition 1} & \multirow[t]{2}{*}{$\begin{array}{l}\text { Medialized to } \\
\text { teardrop }\end{array}$} & \multirow[t]{2}{*}{ Standard offset } & $\begin{array}{l}\text { Flexion: } 26^{\circ} \text { of internal } \\
\text { rotation (range } 10-40^{\circ} \text { ) }\end{array}$ \\
\hline & & & $\begin{array}{l}\text { Extension: } 10^{\circ} \text { of external } \\
\text { rotation (range } 5-35^{\circ} \text { ) }\end{array}$ \\
\hline \multirow[t]{2}{*}{ Condition 2} & \multirow[t]{2}{*}{$\begin{array}{l}\text { Medialized to } \\
\text { teardrop }\end{array}$} & \multirow[t]{2}{*}{ High offset } & $\begin{array}{l}\text { Flexion: } 62^{\circ} \text { of internal } \\
\text { rotation (range } 40-79 \circ \text { ) }\end{array}$ \\
\hline & & & $\begin{array}{l}\text { Extension: } 25^{\circ} \text { of external } \\
\text { rotation }\left(\text { range } 15-63^{\circ}\right)\end{array}$ \\
\hline
\end{tabular}

Table 1. Conditions 1 and 2 were compared to each other to assess effects on anterior and posterior impingement during simulated range of motion, with the only change being the use of standard versus high offset stems, respectively. 


\begin{tabular}{|c|c|c|c|}
\hline $\begin{array}{l}\text { Impingement } \\
\text { Model } \\
\text { Condition }\end{array}$ & $\begin{array}{l}\text { Component } \\
\text { Choice }\end{array}$ & $\begin{array}{l}\text { Global Offset } \\
\text { Change }\end{array}$ & $\begin{array}{l}\text { Range of Motion Until } \\
\text { Impingement }\end{array}$ \\
\hline \multirow[t]{2}{*}{ Condition 3} & \multirow{2}{*}{$\begin{array}{l}\text { Patient-dependent; } \\
\text { recreated } \\
\text { preoperative offset }\end{array}$} & \multirow[t]{2}{*}{ No change } & $\begin{array}{l}\text { Flexion: } 42 \circ \text { of internal } \\
\text { rotation (range } 22-54 \circ \text { ) }\end{array}$ \\
\hline & & & $\begin{array}{l}\text { Extension: } 24 \circ \text { of external } \\
\text { rotation (range } 12-34^{\circ} \text { ) }\end{array}$ \\
\hline \multirow[t]{2}{*}{ Condition 4} & & \multirow[t]{2}{*}{$\begin{array}{l}-4 \mathrm{~mm} \text { global offset } \\
\text { from preop }\end{array}$} & $\begin{array}{l}\text { Flexion: } 22^{\circ} \text { of internal } \\
\text { rotation (range } 8-33^{\circ} \text { ) }\end{array}$ \\
\hline & & & $\begin{array}{l}\text { Extension: } 8^{\circ} \text { of external } \\
\text { rotation (range } 3-16^{\circ} \text { ) }\end{array}$ \\
\hline \multirow[t]{2}{*}{ Condition 5} & & \multirow[t]{2}{*}{$\begin{array}{l}+4 \mathrm{~mm} \text { global } \\
\text { offset from preop }\end{array}$} & $\begin{array}{l}\text { Flexion: } 62^{\circ} \text { of internal } \\
\text { rotation (range } 47-79 \circ \text { ) }\end{array}$ \\
\hline & & & $\begin{array}{l}\text { Extension: } 40^{\circ} \text { of external } \\
\text { rotation (range } 25-50^{\circ} \text { ) }\end{array}$ \\
\hline
\end{tabular}

Table 2. Conditions 3, 4, and 5 were compared to one another to assess effects on anterior and posterior impingement during simulated range of motion. Condition 3 was the basis for the designs of Conditions 4 and 5, for which the global offset was decreased and increased, respectively.

\section{Discussion}

In this study, we aimed to evaluate the difference in rate of dislocation between standard and high offset stems, and the degrees within the extension-flexion cycle at which impingement occurs. Our retrospective analysis of the dislocation rates after primary THA determined that $96 \%$ of patients that suffered a THA dislocation had a standard offset component. Only 2 of the 51 dislocations had a high offset stem, while $49 \%$ of the entire cohort of THAs utilized high offset stems. Additionally, a novel computer software program was utilized to model ROM associated with standard versus high offset stems. Our analysis revealed that high offset stems facilitated greater ROM before bony impingement relative to standard offset stems. For flexion, each $1 \mathrm{~mm}$ of offset gain/loss equated to a $5 \mathrm{~mm}$ increase/decrease in internal rotation until impingement. For extension, each $1 \mathrm{~mm}$ of offset gain/loss equated to $4 \mathrm{~mm}$ of external rotation gain/loss.

Increasing femoral offset has been shown to increase ROM, restore hip biomechanics, and reduce occurrence of impingement and implant failure by increasing the strength of the abductor muscles and decreasing the polyethylene wear rate ${ }^{2,4-8}$. Thus, increasing offset increases ROM and presumably helps mitigate the risk of instability and dislocation.

Our retrospective review of 12,365 patients shows that patients who receive high offset stems have a lower rate of dislocation than those with standard offset stems. The results of our impingement model, which simulated patients with a high risk for instability, suggest that the use of high offset stems is protective of dislocation ${ }^{9}$. In the setting of high-risk THA due to a stiff spine or spinal fusion, surgeons should consider the use of high-offset stems and pay careful attention to offset restoration. Further study of this issue is clearly needed to define parameters for the use of high offset stems in a population at high risk for dislocation after THA. 


\section{References}

1. Hayashi S, Nishiyama T, Fujishiro T, Hashimoto S, Kanzaki N, Nishida K, et al. Excessive femoral offset does not affect the range of motion after total hip arthroplasty. Int Orthop. 2013;37(7):1233-7.

2. McGrory BJ, Morrey BF, Cahalan TD, An KN, Cabanela ME. Effect of femoral offset on range of motion and abductor muscle strength after total hip arthroplasty. J Bone Joint Surg Br. 1995;77(6):865-9.

3. Matsushita A, Nakashima Y, Jingushi S, Yamamoto T, Kuraoka A, Iwamoto Y. Effects of the femoral offset and the head size on the safe range of motion in total hip arthroplasty. J Arthroplasty. 2009;24(4):646-51.

4. Lecerf G, Fessy MH, Philippot R, Massin P, Giraud F, Flecher X, et al. Femoral offset: Anatomical concept, definition, assessment, implications for preoperative templating and hip arthroplasty. Orthopaedics \& Traumatology: Surgery \& Research. 2009;95(3):210-9.

5. Spalding T. Effect of femoral offset on motion and abductor muscle strength after total hip arthroplasty. The Journal of bone and joint surgery British volume. 1996;78(6):997-.

6. Yamaguchi T, Naito M, Asayama I, Ishiko T. Total hip arthroplasty: the relationship between posterolateral reconstruction, abductor muscle strength, and femoral offset. Journal of Orthopaedic Surgery. 2004;12(2):164-7.

7. Devane P, Home G, Winemaker M, Bourne R, Rorabeck C. The effect of restoring femoral offset during THR on 3D volumetric wear. J Bone Joint Surg (Br). 1997;79(Supplement (4S)):385.

8. Sakalkale DP, Sharkey PF, Eng K, Hozack WJ, Rothman RH. Effect of femoral component offset on polyethylene wear in total hip arthroplasty. Clin Orthop Relat Res. 2001(388):125-34.

9. Bottle A, Parikh S, Aylin P, Loeffler M. Risk factors for early revision after total hip and knee arthroplasty: National observational study from a surgeon and population perspective. PLoS One. 2019;14(4):e0214855. 